\title{
Prostate Neuroendocrine Neoplasm
}

National Cancer Institute

\section{Source}

National Cancer Institute. Prostate Neuroendocrine Neoplasm. NCI Thesaurus. Code C5545.

A neoplasm with neuroendocrine differentiation that arises from the prostate gland. 